\title{
Changes to signal peptide and the level of transforming growth factor- $\beta 1$ due to T869C polymorphism of TGF $\beta 1$ associated with lupus renal fibrosis
}

\author{
Hani Susianti ${ }^{1 *}$, Kusworini Handono ${ }^{1}$, Basuki B Purnomo ${ }^{2}$, Nashi Widodo ${ }^{3}$, Atma Gunawan $^{4}$ and Handono Kalim ${ }^{4}$
}

\begin{abstract}
Lupus Nephritis (LN) is a serious manifestation of lupus that can lead to End Stage Renal Disease (ESRD). Fibrosis is the main feature of ESRD, and it is likely influenced by Transforming Growth Factor Beta1 (TGF $\beta 1$ ). The T869C gene polymorphism of TGF $\beta 1$ is assumed to change the signal peptide, that has potential to interfere the urine production and renal protein expression of TGF $\beta 1$. The influence of T869C gene polymorphism on TGF $\beta 1$ production and renal fibrosis was evaluated in this study. Subjects were 45 patients $L N$ with renal fibrosis and 45 participants without renal fibrosis as control, that were recruited from 2011 to 2013.Their urinary TGF $\beta 1$ levels and TGF $\beta 1$ gene polymorphisms were examined. All lupus patients underwent renal biopsy to assess their protein expression of TGF $\beta 1$ in the renal tissue by immunohistochemistry and their renal fibrosis by morphometry and chronicity index. Changes in the signal peptide interaction with Signal Recognition Particle (SRP) and translocon of endoplasmic reticulum were analyzed by Bioinformatics. Levels of urinary and protein expression of TGF $\beta 1$ increased in the LN with renal fibrosis group. There were significant differences in levels of urinary TGF $\beta 1$ in T, C allele and TT, TC, CC genotypes between case and control groups. Furthermore, patients with $C$ allele are 3.86 times more at risk of renal fibrosis than $T$ allele. The $C$ allele encodes proline, which stabilizes the interaction of the TGF $\beta 1$ signal peptide with SRP and translocon, resulting in elevation of TGF $\beta 1$ secretion. Our results indicated that T869C gene polymorphism of TGF $\beta 1$ changes the signal peptide, that contributes to the production of urinary TGF $\beta 1$ and affects renal fibrosis in lupus nephritis.
\end{abstract}

Keywords: T869C gene polymorphism of TGF $\beta 1$; Signal peptide; Urinary TGF $\beta 1$ level; Renal fibrosis; Lupus nephritis

\section{Introduction}

One serious manifestation of lupus is lupus nephritis (LN), which occurs in $40 \%-60 \%$ of patients and can lead to End Stage Renal Disease (ESRD) (Contreras et al. 2005; Mok 2005). Renal fibrosis is the principal feature of ESRD, and TGF $\beta 1$ are assumed to have a significant role in the profibrotic effect (Chatziantoniou and Dussaule 2005; Liu 2006). Regulation of TGF $\beta 1$ production is complicated, but $54 \%$ of its is thought to be mediated by genetics (Awad et al. 1998; Zuccardi et al. 2007). The T869C polymorphism is probably associated with the production of TGF $\beta 1$ (Wang et al. 2010). This polymorphism causes

\footnotetext{
* Correspondence: hanisusianti@yahoo.com

1Department of Clinical Pathology, Faculty of Medicine Brawijaya University/ Dr. Saiful Anwar Hospital, Malang, Indonesia

Full list of author information is available at the end of the article
}

leucine to change into proline at codon 10 in the signal peptide of TGF $\beta 1$. The changing of the signal peptide is likely to interfere the transport of TGF $\beta 1$ to the endoplasmic reticulum that may affect TGF $\beta 1$ production and renal fibrosis. Therefore, the effects of T869C gene polymorphism on TGF $\beta 1$ transport, TGF $\beta 1$ production and renal fibrosis still need to be elucidated.

The study of TGF $\beta 1$ gene polymorphism in lupus patients in Taiwan and Japan showed that the TGF $\beta 1$ gene polymorphism was not associated with $\mathrm{LN}$ ( $\mathrm{Lu}$ et al. 2004; Wang et al. 2007). However, a study in Colombia suggested that TGF $\beta 1$ gene polymorphism is associated with the occurrence of LN (Zuccardi et al. 2007). The study by Wang et al. (2005) and Hanafy and Abdo (2011) showed that T869C and G915C polymorphisms of TGFB1 gene were related to the progression of liver 
fibrosis in patients with chronic Hepatitis. But, study by Xaubet et al. (2003) showed that T869C polymorphism of TGFB1 gene was not related to the progression of lung fibrosis. The effect of TGF $\beta 1$ gene polymorphism in LN patients is still very little studied, especial studies that are associated with renal fibrosis of LN. The increasing expression levels of TGF $\beta 1$ in the kidneys and urine of patients with crescentic nephritis was associated with fibrosis (Goumenos et al. 2005). Otherwise, the up regulation of urinary TGF $\beta 1$ was not significantly correlated to renal fibrosis but associated with the LN activity (Chan et al. 2004). The role of TGF $\beta 1$ in LN and renal fibrosis is still debatable. Therefore, this study evaluated the correlation between the protein expression of TGF $\beta 1$ in renal tissue and urine of LN patients with renal fibrosis. Additionally, this study also examined the T869C polymorphism change interaction among TGF $\beta 1$ signal peptide with the Signal Recognition Particle (SRP) and translocon that possibly interfere with TGF $\beta 1$ transport into the endoplasmic reticulum. This phenomenon explains the role of TGF $\beta 1$ in LN pathogenesis with excessive fibrosis.

\section{Results}

The data show that the majority of LN patients is female (Table 1), which is consistent with the theory that women are more often affected by SLE, due to the sex hormone influence (Hahn 2008). Prolonged illness in the case group was $19.88 \pm 23.10$ months, whereas the control group was $15.53 \pm 11.89$ months $(p=0.793)$. Levels of urinary TGF $\beta 1$ in the case group were higher compared to those of the control group. The most of case

Table 1 Demographic and laboratory data characteristics of groups

\begin{tabular}{|c|c|c|}
\hline & $\begin{array}{l}\text { Case group } \\
(n=45)\end{array}$ & $\begin{array}{l}\text { Control group } \\
(n=45)\end{array}$ \\
\hline \multicolumn{3}{|l|}{ Gender: } \\
\hline Female, $n(\%)$ & $42(93.3)$ & $42(93.3)$ \\
\hline Male, $n(\%)$ & $3(6.7)$ & $3(6.7)$ \\
\hline Age (years) & $28.0 \pm 8.3$ & $30.1 \pm 5.6$ \\
\hline Serum Creatinine (mg/dl) & $1.69 \pm 3.91$ & $0.60 \pm 0.11^{*}$ \\
\hline Protein Urine (mg/dl) & $768.12 \pm 700.98$ & $57.42 \pm 56.71^{*}$ \\
\hline Creatinine Urine (mg/dl) & $77.46 \pm 59.78$ & $135.03 \pm 104.05^{*}$ \\
\hline TGF $\beta 1$ Urine (pg/ml) & $65.91 \pm 91.20$ & $23.68 \pm 9.87^{*}$ \\
\hline \multicolumn{3}{|l|}{ Genotype T869C: } \\
\hline$\Pi, n(\%)$ & $12(26.6)$ & $31(68.8)^{*}$ \\
\hline $\mathrm{TC}, n(\%)$ & $15(33.4)$ & $7(15.6)$ \\
\hline$C C, n(\%)$ & $18(40.0)$ & $7(15.6)^{*}$ \\
\hline
\end{tabular}

Note: Values present as mean \pm standard deviations, except gender and genotype T869C; \%: percentage. ${ }^{*}=p$ - value of $<0.05$ : there is significant difference between case and control groups. group had CC genotype (40\%), whereas in the control group had TT genotype $(68.8 \%)$.

Between groups the levels of urinary TGF $\beta 1$ in the $T$ and $\mathrm{C}$ allele or the TT, TC and CC genotype were significantly different (Table 2), and the highest in genotype $\mathrm{CC}$ (Figure 1). The data suggested that the $\mathrm{C}$ allele contributed to increasing the levels of urinary TGF $\beta 1$. Risk Estimation results indicate that $\mathrm{LN}$ patients with $\mathrm{C}$ allele had 3.8 times (95\% CI 2.04-7.29; $\mathrm{p}=0.00$ ) higher incidences of fibrosis compared to $\mathrm{T}$ allele.

Low chronicity index scores $(<4)$ were found in 27 $(46.6 \%)$ cases and high chronicity index scores $(\geq 4)$ were found in 18 cases $(31.0 \%)$. Low percentage of renal fibrosis $(\leq 5 \%)$ were found in 16 cases $(30.7 \%)$ and high percentage of renal fibrosis $(>5 \%)$ were found in 23 cases (44.3\%) (Table 3). Further analysis showed that TGF 1 levels had a positive correlation with chronicity index scores $(\mathrm{r}=0.606$; $\mathrm{p}<0.05)$, renal fibrosis $(\mathrm{r}=0.602 ; \mathrm{p}<0.05)$ and protein expression of TGF $\beta 1$ in renal tissue $(r=0.660$; $\mathrm{p}<0.05)$.

The T869C polymorphism alters amino acid leucine into proline in the signal peptide of TGF $\beta 1$. The amino acid substitution affected the structure of the TGF $\beta 1$ signal peptide that in turn altered the properties of the peptide. These structural changes lead to shifting the interaction stability to the Signal Recognition Particle (SRP) and translocon and the proline effect was to reduce transmembrane tendency of TGF $\beta 1$ signal peptide (Figure 2).

\section{Discussion}

The results of this study indicated that there were significant differences between the urinary TGF $\beta 1$ levels of LN cases with renal fibrosis and those of the control group. These results are consistent with Goumenos et al. (2005) who stated that there was an increase in TGF $\beta 1$ expression in renal tissue, and its levels in urine patients with crescentic nephritis that was associated with fibrosis. TGF $\beta 1$ induces fibrosis during tissue repair process and contribute to the pathogenesis of a variety of glomerular diseases. However, the research by Chan et al. (2004) mentioned that TGF- $\beta 1$ mRNA expression was not significantly correlated with renal fibrosis but significantly correlated with SLEDAI scores and histological activity index. The difference results of our study with Chan et al. (2004) may be due to the different sampling time. A long illness case subjects in our study were $19.88 \pm 23.10$ months, so that stands out was the chronic state of disorder, not a state of acute inflammation.

The T869C polymorphisms of TGF $\beta 1$ gene replaced leucine into proline at TGF $\beta 1$ signal peptide. The amino acid substitution from leucine into proline changed the hydrophobic region of the TGF $\beta 1$ signal peptide that shifted its binding pattern to SRP and translocon. 
Table 2 Relationship between allele and genotypes of T869C and protein expression of TGF $\beta 1$ or urinary TGF- $\beta 1$ levels

\begin{tabular}{|c|c|c|c|c|c|c|c|}
\hline & & \multicolumn{3}{|c|}{ Urinary TGF $\beta 1$ levels (pg/ml) } & \multicolumn{3}{|c|}{ Protein expression of TGF $\beta 1$ in renal tissues (\%) } \\
\hline & & $\begin{array}{l}\text { Case group } \\
(\mathrm{n}=45)\end{array}$ & $\begin{array}{l}\text { Control group } \\
(n=45)\end{array}$ & $\mathrm{p}$ value & $\begin{array}{l}\text { Case group } \\
(n=35)\end{array}$ & $\begin{array}{l}\text { Control group } \\
(n=10)\end{array}$ & $\mathrm{p}$ value \\
\hline \multirow[t]{2}{*}{ Allele } & T & $48.99 \pm 28.89$ & $24.87 \pm 9.9$ & $<0.01$ & $52.68 \pm 21.13$ & $49.69 \pm 26.69$ & $<0.01$ \\
\hline & C & $78.83 \pm 116.66$ & $19.99 \pm 8.37$ & $<0.01$ & $56.51 \pm 22.42$ & $23.57 \pm 6.72$ & $<0.01$ \\
\hline \multirow[t]{3}{*}{ Genotype } & $\pi$ & $46.75 \pm 21.64$ & $24.79 \pm 10.48$ & 0.03 & $47.00 \pm 21.02$ & $17.60 \pm 7.12$ & 0.14 \\
\hline & TC & $52.57 \pm 38.83$ & $25.47 \pm 6.76$ & 0.01 & $63.20 \pm 14.68$ & $26.0 \pm 14.71$ & 0.01 \\
\hline & $\mathrm{CC}$ & $89.78 \pm 137.71$ & $16.86 \pm 8.04$ & $<0.01$ & $54.60 \pm 25.01$ & $27.00 \pm 7.07$ & 0.15 \\
\hline
\end{tabular}

Note: Values present as mean \pm standard deviations, \%: percentage, p-value of <0.05: significant difference.

Proline has a cyclic structure that will change the alpha helix and increase the hydrophobicity of the core of signal peptide (Gu et al. 2012; Crilly et al. 2002). These changes might affect the transport of TGF $\beta 1$ into the endoplasmic reticulum that contributes to cytokine production. This result corresponds to Dunning et al. (2003) which found that the replacement of leucine to proline at codon 10 of TGF $\beta 1$ signal peptide could potentially alter the secretion of cytokine. Moreover, the substitution from leucine into proline led to an increase of 2.8 times of TGF $\beta 1$ secretion (Dunning et al. 2003).

The study indicated that the proline at codon ten was associated with increased TGF $\beta 1$ secretion rate and that TGF $\beta 1$ levels increased in accordance with the change of $\mathrm{T}$ to $\mathrm{C}$ allele. The TT genotype had lowest levels, and CC genotype had highest levels of TGF $\beta 1$ both in cases and control groups. Moreover, CC genotype had more prevalent in renal fibrosis and risk of ESRD. These results are consistent with Fernandez \& Molina (2009) research that found the TGF $\beta 1$ polymorphism correlated with a higher level of TGF $\beta 1$ protein. This polymorphism is more common in Africans than in Caucasians, and African races have a worse prognosis in LN (Contreras et al. 2005; Fernandez \& Molina 2009). Moreover, the TGF $\beta 1$ gene polymorphism may be associated with clinical manifestations and prognosis of the disease (Babel et al. 2004; August et al. 2009)

\section{Conclusion}

T869C gene polymorphism of TGF $\beta 1$ changes properties, pattern and binding stability of TGF $\beta 1$ signal peptide with SRP and translocon that contributes to the production of urinary TGF $\beta 1$ and renal fibrosis in lupus nephritis.

\section{Material and methods \\ Study design}

A case control study was conducted. The study was conducted after approval by the ethics committee of Medical faculty of Brawijaya University, Malang, Indonesia. Informed consent was obtained from all patients for being included in the study. This study was conducted

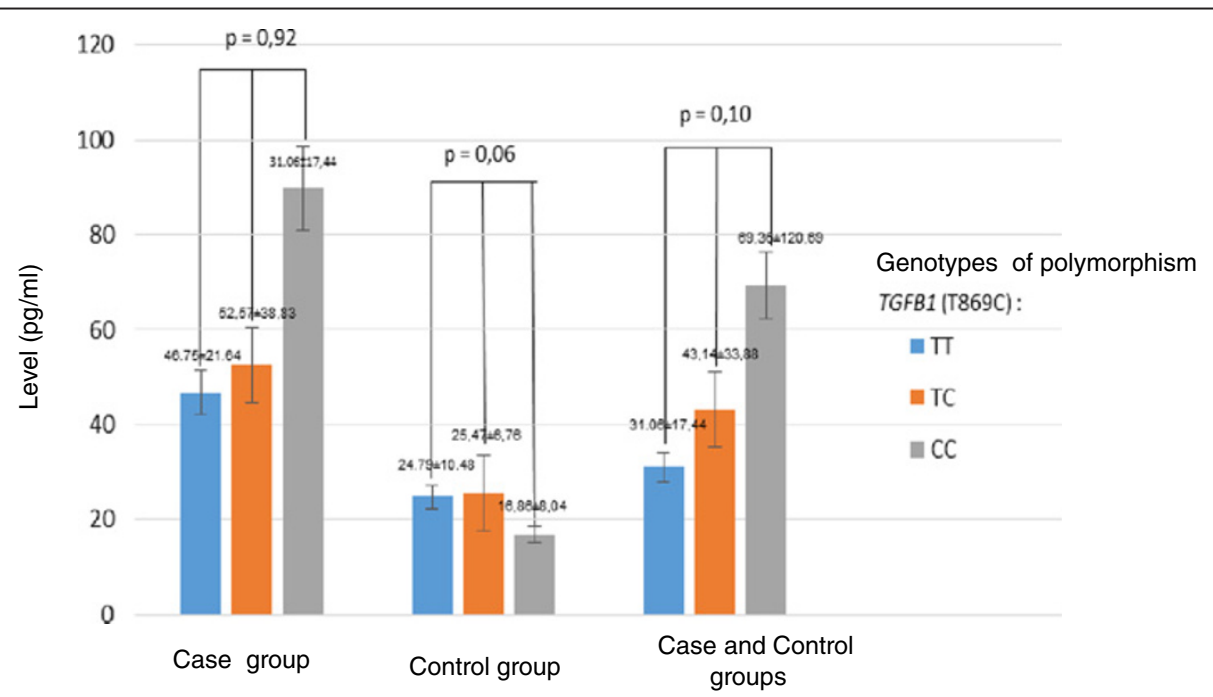

Figure 1 The levels of urinary TGF $\beta 1$ in TT, TC, CC genotypes in the case and control groups were significantly different. The CC genotype in the case group had the highest of urinary TGF $\beta 1$. 
Table 3 Relationship between chronicity index scores and renal fibrosis to levels of urinary and protein expression of TGF $\beta 1$

\begin{tabular}{|c|c|c|c|c|c|c|}
\hline & $\begin{array}{l}\text { High chronicity } \\
\text { index score } \\
(n=18)\end{array}$ & $\begin{array}{l}\text { Low chronicity } \\
\text { index score } \\
(n=27)\end{array}$ & $p$ value & $\begin{array}{l}\text { High percentage } \\
\text { of renal fibrosis } \\
\qquad(n=23)\end{array}$ & $\begin{array}{l}\text { Low percentage } \\
\text { of renal fibrosis } \\
\qquad(n=16)\end{array}$ & $p$ value \\
\hline Urinary TGF $\beta 1$ levels (pg/ml) & $134.31 \pm 31.65$ & $39.32 \pm 32.45$ & 0.00 & $49.90 \pm 30.05$ & $34.60 \pm 33.64$ & 0.00 \\
\hline Protein expression of TGF $\beta 1$ in renal tissues (\%) & $48.78 \pm 24.89$ & $46.35 \pm 24.09$ & 0.76 & $60.65 \pm 18.66$ & $28.42 \pm 14.13$ & 0.00 \\
\hline
\end{tabular}

Note: Values present as mean \pm standard deviations, \%: percentage, $\mathrm{p}$-value of $<0.05$ : significant difference.

between February 2011 and October 2013 in the Department of Internal Medicine and Clinical Pathology, Dr. Saiful Anwar Hospital, Malang, Indonesia.

\section{Population}

The cases were 45 patients LN with renal fibrosis and as the controls were 13 lupus patients without renal fibrosis and 32 healthy controls. All subjects' blood samples taken for DNA sequencing and urinary sample for TGF $\beta 1$ level examination by ELISA. The diagnosis of lupus nephritis was in accordance with the ACR (American Collage of Rheumatology) criteria 1997 and renal biopsies were performed on 58 patients with lupus. Informed consent was obtained from all patients before being included in the study.

\section{Laboratory assays}

Urinary TGF $\beta 1$ was measured by sandwich enzyme-linked immunosorbent assay (ELISA) using a specific antibody for human TGF- $\beta 1$ (Quantikine, R\&D, Minneapolis, USA). Limit measurements up to $1000 \mathrm{pg} / \mathrm{ml}$ with a variation coefficient of inter assay $2.1 \%$ and $7.1 \%$ intra assay. Morning urine samples were taken aseptically, put in a sterile container, then immediately centrifuged and stored at $-80^{\circ} \mathrm{C}$ until analyzed. Creatinine and protein levels were analyzed using the kit from Roche (Roche, New York, USA) according to the protocol in the kit.

\section{Isolation of DNA and sequencing}

DNA isolation was performed using Dneasy Blood and Tissue Kit (Qiagen) from $200 \mu \mathrm{L}$ venous blood samples.
A

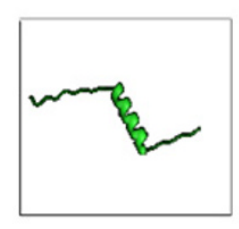

A1

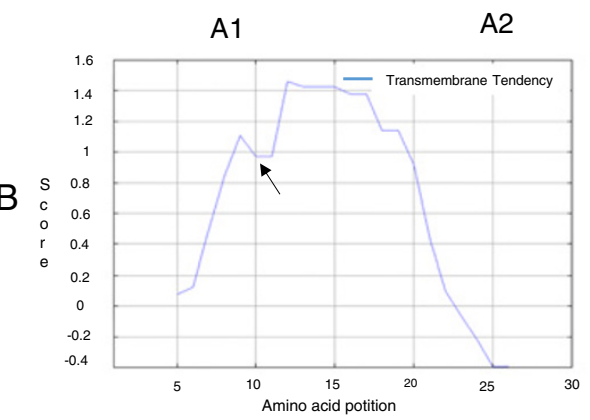

B1

A2
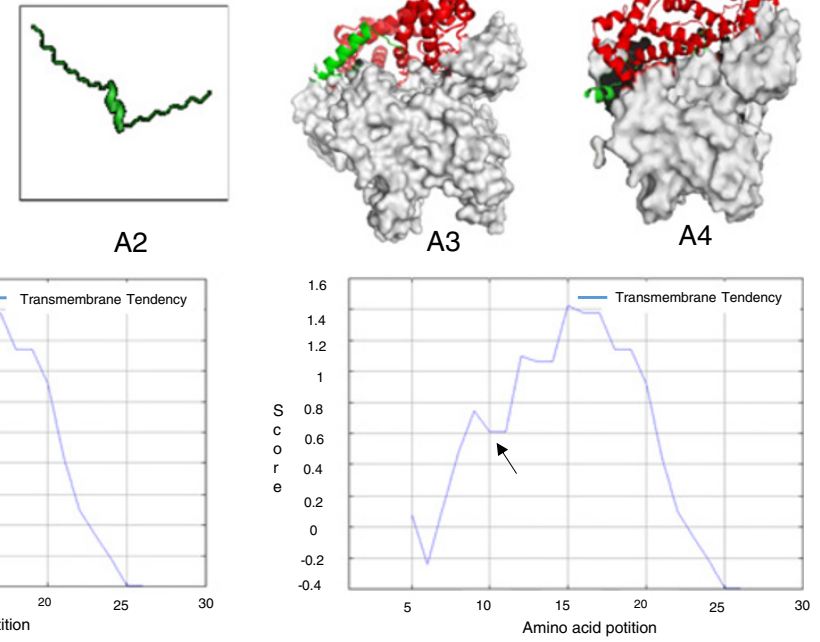

B2

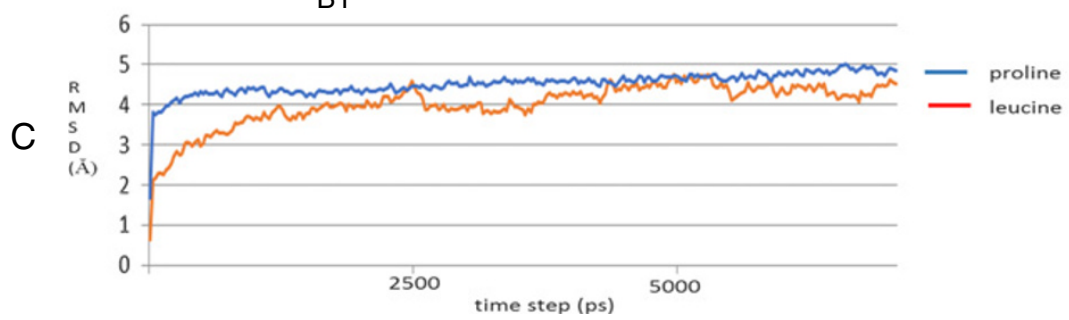

Figure 2 The T869C polymorphism changes the structure and properties of the TGF $\beta 1$ signal peptide. The polymorphism changes Leucine (A1) to Proline (A2) that breaks the helix structure that alters the interaction of TGF $\beta 1$ signal peptides (green) with Signal Recognition Particle (SRP; red) and translocon (gray) (A3 and A4). The proline type of TGF $\beta 1$ signal peptide reduces the values on transmembrane tendency (B2) and bind more stably to the protein partner (C). 
Samples were taken from all participants and examined by PCR using primers: 5'-d CTAGGTTATTTCCGTGGG3' (forward primer) and 5'-d CCTTGGCGTAGTAGTCG3' (reverse primer). Genomic DNA (100 ng) in amplification with 0.5 units of Taq DNA polymerase 2,5 $\mu \mathrm{M}$ dNTPs. PCR was conditioned $95^{\circ} \mathrm{C}$ for five minutes, followed by 30 cycles at $95^{\circ} \mathrm{C}$ for 30 seconds, then $50^{\circ} \mathrm{C}$ for $30 \mathrm{sec}$ and $72^{\circ} \mathrm{C}$ for 30 secs and final extension for $10 \mathrm{~min}$ at $72^{\circ} \mathrm{C}$ (Wang et al. 2010). PCR results, then sequenced using ABI Prism Sequence Detector System (Applied Biosystems).

\section{In silico investigation of signal peptide of T869C TGF $\beta 1$ gene polymorphisms}

3D structure (Protein Modeling) of the signal peptide of T869C TGF- $\beta 1$ gene polymorphisms for leucine and proline at codon 10 types are not available in the database, so the structure was predicted using Phyre2 then validated using PROCHECK. Signal Recognition Particle (SRP ) Model 54 M domain (1QB2) and translocon model (Sec61_2wwb) were taken from PDB BANK (http://www.rscb.org) then validated using PROCHECK based on Ramachandran plot analysis. Protein docking using Vega (Escher NG) to estimate the interaction of TGF $\beta 1$ leucine and proline type with SRP-M domain and translocon. Docking results were then analyzed for molecular interactions. The stability of the bond between TGF $\beta 1$, SRP and translocon were simulated using Amber 03, Yasara Molecular Dynamic Simulation and visualized using the Pymol molecular graphics system.

Immunohistochemistry of TGF $\beta 1$ expression in renal tissues Specimens of tissue biopsy were preserved in $10 \%$ formalin and then cut to a thickness of $4 \mu \mathrm{m}$. Sections were incubated with monoclonal antibody against TGF $\beta 1$ (R\&D, Minneapolis, USA). Biotin-labeled second antibody was incubated with the enzyme alkaline phosphatase labeled streptavidin. All stages were performed at room temperature, followed by washing in PBS. Staining was completed after $10 \mathrm{~min}$ incubation in 3,3'-diaminobenzidine in Tris buffered saline. Sections were finally counterstained in hematoxylins Mayer. The results of immunohistochemical examination were assessed by calculating the percentage of stained cells with the monoclonal anti-bodies against TGF $\beta 1$ within 500 cells of renal tissue.

\section{Measurement of renal fibrosis by morphometry}

Morphometry analysis was used to assess fibrosis levels of the renal tissue. Staining sections used Masson 's trichrome. Digital images of the sections were photographed using Olympus microscope and Olyvia software. Assessment of the fibrosis then was performed using C5S Adobe Photoshop (Adobe Systems Corporation, San Jose, CA) (Dahab et al. 2004). Assessment of the fibrotic tissue is done by avoiding capsule and arterial adventitia areas.
Fibrosis percentages were obtained by dividing the blue area (fibrotic tissue) with a total area expressed as pixels. Percentage of renal fibrosis $\leq 5 \%$ describes the state of the kidneys are normal.

\section{Lupus nephritis chronicity index assessment}

Histopathological chronicity index of lupus nephritis was determined by renal biopsy and examined by two expert Anatomical Pathologists. The final score was obtained by summing all the scores from each of the following parameters: glomerular sclerosis, crescent fibrous structure, tubular atrophy and Interstitial fibrosis. Scores obtained from the above assessment were then added up and the number range between 1-12 (Dooley 2007). High chronicity index score $(\geq 4)$ showed less response to therapy, resulting in a poorer prognosis.

\section{Statistical analysis}

Statistical Analysis used a comparison test (t-test or Mann-Whitney and one-way ANOVA or Kruskal-Wallis), Correlation Test (Pearson or Spearmann), odd's ratio and descriptions of the structure or interaction of TGF- $\beta 1$ signal peptide with SRP and translocon.

\section{Human rights statements and informed consent}

All procedures followed were in accordance with the ethical standards of the responsible committee on human experimentation (institutional and national) and with the Helsinki Declaration of 1975, as revised in 2008. Informed consent was obtained from all patients for being included in the study.

\section{Abbreviations}

LN: Lupus nephritis; ESRD: End Stage Renal Disease; SRP: Signal Recognition Particle; ACR: American Collage of Rheumatology.

\section{Competing interests}

The authors declare that they have no conflict of interests.

\section{Authors' contributions}

$\mathrm{HS}$ wrote the manuscript and participated in the study design. $\mathrm{KH}, \mathrm{BBP}$ and HK drafted and revised the manuscript. AG performed renal biopsies. NW performed bioinformatic analyses and revised the manuscript. All authors read and approved the final manuscript.

\section{Acknowledgements}

We would like to thank the Director of Syaiful Anwar Hospital and Dean of Medical Faculty Brawijaya University, Malang for the provided grant and all of those who involved in this research.

\section{Author details}

'Department of Clinical Pathology, Faculty of Medicine Brawijaya University/ Dr. Saiful Anwar Hospital, Malang, Indonesia. ${ }^{2}$ Department of Urology, Faculty of Medicine Brawijaya University/Dr. Saiful Anwar Hospital, Malang, Indonesia. ${ }^{3}$ Department of Biology, Faculty of Science, Brawijaya University, Malang, Indonesia. ${ }^{4}$ Department of Internal Medicine, Faculty of Medicine Brawijaya University/Dr. Saiful Anwar Hospital, Malang, Indonesia.

Received: 10 June 2014 Accepted: 2 September 2014 Published: 10 September 2014 


\section{References}

August P, Sharma V, Ding R (2009) Transforming growth factor beta and excess burden of renal disease. Trans Am Clin Climatol Assoc 120:61-72

Awad MR, Gamel A, Hasleton P, Turner DM, Sinnott PJ, Hutchinson IV (1998) Genotypic variation in the transforming growth factor-[beta]1 gene: association with transforming growth factor-[beta]1 production, fibrotic lung disease, and graft fibrosis after lung transplantation. Transplantation 66(8):1014-1020

Babel N, Cherepnev G, Kowalenko A, Horstrup J, Volk HD, Reinke P (2004) Nonimmunologic complications and gene polymorphisms of immunoregulatory cytokines in long-term renal transplants. Kidney Int 66(1):428-432

Chan RW, Lai FM, Li EM, Tam LS, Wong TY, Szeto CY (2004) Expression of chemokine and fibrosing factor messenger RNA in the urinary sediment of patients with lupus nephritis. Arthritis Rheum 50(9):2882-2890

Chatziantoniou C, Dussaule JC (2005) Insights into the mechanisms of renal fibrosis : is it possible to achieve regression? Am J Physiol 289:227-234

Contreras G, Pardo V, Cely C (2005) Factors associated with poor outcomes in patients with lupus nephritis. Lupus 14:890-895

Crilly A, Hamilton J, Clark CJ, Jardine A, Madhok R (2002) Analysis of transforming growth factor beta1 gene polymorphisms in patients with systemic sclerosis. Ann Rheum Dis 61:678-681

Dahab GM, Kheriza MM, El-Beltagi HM (2004) Digital quantification of fibrosis in liver biopsy sections: Description of a new method by Photoshop software. J Gastroenterol Hepatol 19:78

Dooley MA (2007) Clinical and Laboratory Features of Lupus Nephritis. In: Wallace DJ, Hahn BH (ed) Dubois' Lupus Erythematosus 7th edition. Lippincott Williams \& Wilkins, Philadelphia, pp 1112-1124

Dunning AM, Ellis PD, McBride S, Kirschenlohr HL, Healey CS, Kemp PR, Luben RN, Chang J, Mannermaa A, Kataja V, Pharoah PD, Easton DF, Ponder BA, Metcalfe JC (2003) A transforming growth Factor betal signal peptide variant increases secretion in vitro and is associated with increased incidence of invasive breast cancer. Cancer Res 63:2610-2615

Fernandez NG, Molina MLM (2009) TGF- $\beta$ made easy. Open Urol Nephrol J 2:1-5

Goumenos DS, Kalliakmani P, Tsakas S, Sotsiou F, Vlachojannis JG (2005) Urinary transforming growth factor-beta 1 as a marker of response to immunosuppressive treatment, in patients with crescentic nephritis. BMC Nephrol 6:16-23

Gu X, Ji X, Shi LH, Yi CH, Zhao YP, Wang AH, Lu LG, Yu WB, Gao CF (2012) Transforming growth factor beta1 gene variation Leu10Pro affects secretion and function in hepatic cells. Dig Dis Sci 57:2901-2909

Hahn BH (2008) Systemic Lupus Erythematosus. In: Fauci AS, Braunwald E, Kasper $\mathrm{DL}$, et al. (ed) Harrison's Principle of Internal Medicine, 17th edition. McGraw Hill, USA, pp 2075-2082

Hanafy SM, Abdo A (2011) Impact of single nucleotide polymorphism of TGF- $\beta 1$ gene (SNP-Codon10) on hepatocellular carcinoma risk in egyptian patients following HCV infection. Aust J Basic Appl Sci 5(9):1814-1821

Liu Y (2006) Renal Fibrosis : New insight into the Pathogenesis and theraupetics. J Kidney Int 69:213-217

Lu LY, Cheng HH, Sung PK (2004) Single nucleotide polymorphism of TGF beta1 in taiwanese patients with systemic lupus erythematosus. J Microbiol Immunol Infect 37(3):145-152

Mok CC (2005) Prognostics factors in lupus nephritis. Lupus 14:39-44

Wang H, Mengsteab S, Tag CG, Gao CF, Hellerbrand C, Lammert F, Gressner AM, Weiskirchen R (2005) World J Gastroenterol 11:1929

Wang B, Morinobu A, Kanagawa S (2007) TGF beta 1 gene polymorphism in Japanese patients with SLE. Kobe J Med Sci 53:15-23

Wang Y, Hou X, Li Y (2010) Association between transforming growth factor $\beta$-1 polymorphisms and atrial fibrillation in essential hypertensive subjects. J Biomed Sci 17(23):1-5

Xaubet A, Arguedas AM, Lario S, Ancochea J, Morell F, Manzano JR, Becerra ER, Arias JMR, In ĩigo P, Sanz S, Campistol JM, Mullol J, Picado C (2003) Transforming growth factor- $\beta 1$ gene polymorphisms are associated with disease progression in idiopathic pulmonary fibrosis. Am J Respir Crit Care Med 168:431-435

Zuccardi PG, Lopez Y, Giraldo M, Garcia N, Rodriguez L, Ramirez L, Uribe O, Garcia L, Vasquez G (2007) Cytokine gene polymorphisms in colombian patients with systemic lupus erythematosus. Tissue Antigens 70:376-382

doi:10.1186/2193-1801-3-514

Cite this article as: Susianti et al: Changes to signal peptide and the level of transforming growth factor- $\beta 1$ due to T869C polymorphism of TGF $\beta 1$ associated with lupus renal fibrosis. SpringerPlus 2014 3:514.

\section{Submit your manuscript to a SpringerOpen ${ }^{\circ}$ journal and benefit from:}

- Convenient online submission

- Rigorous peer review

- Immediate publication on acceptance

- Open access: articles freely available online

- High visibility within the field

- Retaining the copyright to your article

Submit your next manuscript at $\downarrow$ springeropen.com 